\title{
Synthesis of low-density polyethylene derived carbon nanotubes for activation of persulfate and degradation of water organic micropollutants in continuous mode
}

\author{
Rui S. Ribeiro ${ }^{\text {a, }}$, Octávia Vieira ${ }^{a}$, Rita Fernandes ${ }^{a}$, Fernanda F. Roman ${ }^{\mathrm{a}, \mathrm{b}}$, \\ Jose L. Diaz de Tuesta ${ }^{\text {b, }}{ }^{* *}$, Adrián M.T. Silva ${ }^{a}$, Helder T. Gomes ${ }^{b}$ \\ ${ }^{a}$ Laboratory of Separation and Reaction Engineering - Laboratory of Catalysis and Materials (LSRE-LCM), Faculdade de Engenharia, Universidade do Porto, Rua Dr. \\ Roberto Frias, 4200-465, Porto, Portugal \\ ${ }^{\mathrm{b}}$ Centro de Investigação de Montanha (CIMO), Instituto Politécnico de Bragança, Campus de Santa Apolónia, 5300-253, Bragança, Portugal
}

\section{A R T I C L E I N F O}

\section{Keywords:}

Waste management

Chemical vapour deposition (CVD)

Advanced oxidation processes (AOPs)

Composite polymeric membranes

Contaminants of emerging concern (CECs)

\begin{abstract}
A B S T R A C T
Plastic derived carbon nanotubes (CNTs) were tested as catalysts in persulfate activation for the first time. Four catalysts were prepared by wetness impregnation and co-precipitation (using $\mathrm{Al}_{2} \mathrm{O}_{3}, \mathrm{Ni}, \mathrm{Fe}$ and/or $\mathrm{Al}$ ) and implemented to grow CNTs by chemical vapour deposition (CVD) using low-density polyethylene (LDPE) as carbon feedstock. A catalyst screening was performed in batch mode and the best performing CNTs $\left(\mathrm{CNT} @ \mathrm{Ni}+\mathrm{Fe} / \mathrm{Al}_{2} \mathrm{O}_{3}\right.$-cp) led to a high venlafaxine mass removal rate $\left(3.17 \mathrm{mg} \mathrm{g}^{-1} \mathrm{~h}^{-1}\right)$ in ultrapure water after $90 \mathrm{~min}$ (even with a mixture of micropollutants). Its degradation increased when the matrix was replaced by drinking water and negligibly affected in surface water. A composite polymeric membrane was then fabricated with CNT@Ni+Fe $/ \mathrm{Al}_{2} \mathrm{O}_{3}$-cp and polyvinylidene fluoride (PVDF), a high venlafaxine mass removal rate in surface water being also observed in $24 \mathrm{~h}$ of continuous operation. Therefore, the results herein reported open a window of opportunity for the valorisation of plastic wastes in this catalytic application performed in continuous mode.
\end{abstract}

\section{Introduction}

One of the main constraints hindering the intensification of plastic recycling practices is the lack of economic attractiveness of the resulting products (Miranda et al., 2020). At the same time, one of the main challenges of industrial-scale production of carbon nanotubes (CNTs) by catalytic chemical vapour deposition (CVD) is still its cost (Bazargan and McKay, 2012; Serp et al., 2003). In CVD, nucleation and growth of CNTs usually occur at the surface of metal catalyst particles upon decomposition of a pure hydrocarbon gas under high temperature (typically in the range $700-950{ }^{\circ} \mathrm{C}$ ), followed by a purification step to remove the attached catalyst particles (Lehman et al., 2011; Oberlin et al., 1976). Therefore, it comes as no surprise the fast growth in the number of research studies conducted to explore the potential synergies arising from the use of plastics as feedstock to produce CNTs. The hypothesis raised in those studies is that the stream of a pure hydrocarbon gas (e.g., methane, acetylene, benzene), typically used as carbon source to feed the CVD system, can be replaced by the hydrocarbon gases released upon thermal decomposition of (low-cost) plastic wastes. In this way, the costs associated with CNTs production by catalytic CVD are expected to decrease. Moreover, the use of plastic wastes to produce added-value materials, such as CNTs, is expected to increase the economic attractiveness of plastics recycling. Therefore, the cost-effective, environmentally-friendly, and sustainable production of CNTs is expected to be achieved through this approach (Zhuo and Levendis, 2014).

The current trend towards the synthesis of CNTs from plastics is reflected in the increasing number of research articles (Fig. S1a) and in the nine review articles published since 2012 (Bazargan and McKay, 2012; Nyakuma and Ivase; Okan et al., 2019; Papari et al., 2021; Sharma and Batra, 2020; Utetiwabo et al., 2020; Wang et al., 2020; Williams, 2021; Zhuo and Levendis, 2014). Most of the original research studies on this topic are solely focused on the optimization of the synthesis conditions ( $>75 \%$, Fig. S1b). Nevertheless, some articles also report the application of the resulting CNTs, namely in electrochemical and energy (Cai et al., 2020a, 2020b; Gao et al., 2018; Moo et al., 2019; Pol and Thackeray, 2011; Sridhar and Park, 2020; Veksha et al., 2020; Wen et al., 2014),

\footnotetext{
* Corresponding author.

$* *$ Corresponding author.

E-mail addresses: rsribeiro@fe.up.pt (R.S. Ribeiro), jl.diazdetuesta@ipb.pt (J.L. Diaz de Tuesta).
} 
environmental (Deokar et al., 2017; Gong et al., 2014; Sridhar and Park, 2020), composite filling (Borsodi et al., 2016; Wu et al., 2016) and nanomedicine (Mezni et al., 2017) applications. Although CNTs produced by CVD with pure hydrocarbons (i.e., more expensive) have been shown to be suitable materials for several advanced oxidation processes - AOPs (Duan et al., 2018), such as activated persulfate oxidation (Chen et al., 2018) and catalytic wet peroxide oxidation (Ribeiro et al., 2016b), the environmental applications of CNTs produced from plastics (i.e., less expensive) are still limited to adsorption of oils (Gong et al., 2014) and organic micropollutants (MPs) (Deokar et al., 2017; Sridhar and Park, 2020), and have not been tested yet in AOPs, such as persulfate activation.

The characteristics of CNTs produced by catalytic CVD depend on the operating conditions (e.g., temperature, time, pressure, etc.), and the nature and load of both hydrocarbon gas (carbon source) and metal catalyst (Szabó et al., 2010; Tessonnier et al., 2009). Having all this in mind, in this work four metal catalysts were prepared from $\mathrm{Al}_{2} \mathrm{O}_{3}, \mathrm{Ni}, \mathrm{Fe}$ and/or $\mathrm{Al}$ by using wetness impregnation or co-precipitation methods and employed for the growth of CNTs using low-density polyethylene (LDPE) as carbon feedstock. $\mathrm{Ni}$ and/or $\mathrm{Fe}$ on $\mathrm{Al}_{2} \mathrm{O}_{3}$ transition metal catalysts were selected due to their known activity for the conversion of plastic wastes into CNTs by CVD (Bazargan and McKay, 2012; Williams, 2021). The resulting CNTs were characterized and used in activated persulfate oxidation experiments for the degradation of organic MPs in batch mode. Aqueous solutions of venlafaxine alone, and in mixture with atenolol, metoprolol and citalopram, were used as model systems of organic MPs. Venlafaxine is an antidepressant drug included during the most recent revision of the Watch List of contaminants of emerging concern (CECs) (EU Comission, 2020). The beta-blockers atenolol and metoprolol, and the antidepressant citalopram, have been detected in the environment during monitoring programmes carried out by our group, the reason why they were selected for this study (Barbosa et al., 2018; Sousa et al., 2020).

The effect of the water matrix on the treatment performance was also studied, upon employing drinking water (DW) and surface water (SW), in addition to ultrapure (UP) water; and scavenging tests were performed to infer about the main oxidation species involved in the process. The best performing sample of CNTs was included as active catalytic phase in a poly(vinylidene fluoride) (PVDF) matrix by adapting a methodology previously reported by our group (Vieira et al., 2020). Activated persulfate oxidation experiments for the degradation of venlafaxine in SW were then performed in continuous mode of operation with the resulting composite polymeric membrane, as proof of concept. To the best of our knowledge, CNTs produced from plastics are herein employed for the first time in activated persulfate oxidation for the removal of organic MPs. In this way, prospects are opened for overcoming two relevant issues (plastic solid waste accumulation and water contamination) through a single solution: valorisation of plastic waste through conversion into CNTs to be employed in the removal of water organic micropollutants by activated persulfate oxidation.

\section{Experimental procedure}

\subsection{Materials, chemicals and water matrices}

The materials, chemicals and water matrices used in this study are described in Text S1.

\subsection{Preparation of the catalysts employed in CVD}

Four metal catalysts were prepared from $\mathrm{Al}_{2} \mathrm{O}_{3}$, and/or Ni, Fe and/or $\mathrm{Al}$ nitrate salts, namely by wetness impregnation (wi) of $\mathrm{Al}_{2} \mathrm{O}_{3}$ with (i) $\mathrm{Ni}\left(\mathrm{Ni} / \mathrm{Al}_{2} \mathrm{O}_{3}\right.$-wi) and (ii) $\mathrm{Ni}$ and $\mathrm{Fe}$ simultaneously $\left(\mathrm{Ni}+\mathrm{Fe} / \mathrm{Al}_{2} \mathrm{O}_{3}\right.$-wi); and co-precipitation (cp) of (iii) $\mathrm{Ni}$ and $\mathrm{Fe}$ over $\mathrm{Al}_{2} \mathrm{O}_{3}\left(\mathrm{Ni}+\mathrm{Fe} / \mathrm{Al}_{2} \mathrm{O}_{3}-\mathrm{cp}\right.$ ) and (iv) $\mathrm{Al}, \mathrm{Ni}$ and $\mathrm{Fe}$ simultaneously ( $\mathrm{Ni}+\mathrm{Fe}+\mathrm{Al}-\mathrm{cp})$. Additional experimental details are given in Text S2.

\subsection{Preparation of CNTS}

CNTs were prepared by catalytic CVD, by adapting the procedure previously reported (Diaz de Tuesta et al., 2020). In this case, a Termolab vertical tubular furnace (i.d. $=50 \mathrm{~mm}, L=500 \mathrm{~mm}$ ) with two heating zones controlled independently by EPC3000 controllers was used (Fig. S2). Briefly, a crucible containing $5 \mathrm{~g}$ of the LDPE used as carbon feedstock was held in the top heating zone $\left(450{ }^{\circ} \mathrm{C}\right)$ and $1 \mathrm{~g}$ of one of the four metal catalysts (prepared as described in Section 2.2) was placed on a crucible held in the bottom heating zone $\left(850{ }^{\circ} \mathrm{C}\right)$. For that purpose, the bottom zone was heated at $20^{\circ} \mathrm{C} \min ^{-1}$ until $400{ }^{\circ} \mathrm{C}$, and then the top and bottom zones were heated up to 450 and $850{ }^{\circ} \mathrm{C}$, respectively, also at $20{ }^{\circ} \mathrm{C} \mathrm{min}^{-1}$. The simultaneous thermal decomposition of the polymer (top zone) and catalytic CVD (bottom zone) was then allowed to proceed under a $\mathrm{N}_{2}$ flow $\left(100 \mathrm{~cm}^{3} \mathrm{~min}^{-1}\right)$ for $1 \mathrm{~h}$. Afterwards, the resulting solids were collected from the bottom zone, purified with $50 \mathrm{vol} \% \mathrm{H}_{2} \mathrm{SO}_{4}$ at $140{ }^{\circ} \mathrm{C}$ during $3 \mathrm{~h}$, thoroughly washed with distilled water and dried overnight in oven at $60^{\circ} \mathrm{C}$. The resulting materials were denoted as CNT@ followed by the description of the metal catalyst used for their growth by CVD, namely: CNT@Ni/A$\mathrm{l}_{2} \mathrm{O}_{3}$-wi, $\quad \mathrm{CNT} @ \mathrm{Ni}+\mathrm{Fe} / \mathrm{Al}_{2} \mathrm{O}_{3}$-wi, $\quad \mathrm{CNT} @ \mathrm{Ni}+\mathrm{Fe} / \mathrm{Al}_{2} \mathrm{O}_{3}$-cp, and $\mathrm{CNT@Ni+Fe+Al-cp.} \mathrm{Only} \mathrm{purified} \mathrm{CNTs} \mathrm{were} \mathrm{employed} \mathrm{in} \mathrm{this} \mathrm{study.}$

\subsection{Fabrication of composite polymeric membranes}

The composite polymeric membranes were obtained by including $\mathrm{CNT} @ \mathrm{Ni}+\mathrm{Fe} / \mathrm{Al}_{2} \mathrm{O}_{3}$-cp within a PVDF matrix, by adapting the procedure previously described (Vieira et al., 2020). For that purpose, $3.2 \mathrm{wt} \%$ of powder CNT@Ni+Fe/ $\mathrm{Al}_{2} \mathrm{O}_{3}$-cp was added to the membrane-forming materials, as detailed in Text $\mathrm{S} 3$. The resulting composite membrane (Fig. S3) was denoted as $\mathrm{CNT} @ \mathrm{Ni}+\mathrm{Fe} / \mathrm{Al}_{2} \mathrm{O}_{3}$-cp-PVDF and used in activated persulfate oxidation experiments performed in continuous mode of operation.

\subsection{Characterization techniques}

Scanning electron microscopy (SEM) images were obtained using a FEI Quanta 400FEG ESEM/EDAX Genesis X4Minstrument equipped with an Energy Dispersive Spectrometer (EDS). Before cross-sectional characterization, the membranes were cut under cryogenic conditions through immersion in liquid nitrogen. ImageJ software was used in order to estimate the average thickness of the $\mathrm{CNT} @ \mathrm{Ni}+\mathrm{Fe} / \mathrm{Al}_{2} \mathrm{O}_{3}$-cpPVDF membrane ( $n=10$ measurements). TEM images were obtained using a JEOL 2100, LaB6 filament, transmission electron microscope operating at $200 \mathrm{kV}$. Thermogravimetric analysis (TGA) was performed by heating the sample from 50 to $850{ }^{\circ} \mathrm{C}$ (at $10{ }^{\circ} \mathrm{C} \mathrm{min}{ }^{-1}$ ) under a $\mathrm{N}_{2}$ flow, in a Netzsch STA $490 \mathrm{PC} / 4 / \mathrm{H}$ Luxx thermal analyser. The size of the largest pore of the $\mathrm{CNT} @ \mathrm{Ni}+\mathrm{Fe} / \mathrm{Al}_{2} \mathrm{O}_{3}$-cp-PVDF membrane was determined through the bubble-point method, as described in a previous publication of our group (Silva et al., 2015).

Textural properties, namely specific surface area calculated by the Brunauer, Emmett and Teller (BET) method $\left(S_{\mathrm{BET}}\right)$, and total pore volume ( $V_{\text {Total }}$ ), were determined by $\mathrm{N}_{2}$ physisorption, as previously described (Silva et al., 2019). The concentration of acidic sites at the surface of the materials was determined using the titration technique previously described (Gomes et al., 2010). The pH at point of zero charge ( $\mathrm{pH}_{\mathrm{PZC}}$ ) was obtained by $\mathrm{pH}$ drift tests, as described elsewhere (Ribeiro et al., 2016a). The content of Al, Ni, and/or Fe in the CNTs was determined by inductively coupled plasma optical emission spectrometry (ICP-OES) analysis of the solution resulting from the acidic digestion of the solids, performed as described elsewhere (Ribeiro et al., 2016a).

\subsection{Activated persulfate experiments}

Activated persulfate experiments were performed in batch and 
continuous mode of operation, both at room temperature $\left(22 \pm 2{ }^{\circ} \mathrm{C}\right)$, and without $\mathrm{pH}$ adjustment or added buffers. Nevertheless, the $\mathrm{pH}$ was monitored in selected experiments. The powder CNTs prepared as described in Section 2.3 were used in the experiments performed in batch mode, while experiments in continuous mode were performed with the composite polymeric membrane (CNT@Ni+Fe/ $/ \mathrm{Al}_{2} \mathrm{O}_{3}$-cpPVDF) obtained as described in Section 2.4.

Experiments in batch mode were conducted in a stirred amber glass bottle loaded with $50 \mathrm{~mL}$ of an aqueous solution containing the model pollutant(s). In each run, a calculated amount of SPS was added to obtain the desired concentration of oxidant source $\left(250 \mathrm{mg} \mathrm{L}^{-1}\right)$. After homogenization, the reaction started with the addition of the powder catalyst $\left(0.05\right.$ or $\left.0.25 \mathrm{~g} \mathrm{~L}^{-1}\right)$. Samples were periodically withdrawn, filtered $\left(0.2 \mu \mathrm{m}\right.$ PTFE syringe filters) and kept at $4{ }^{\circ} \mathrm{C}$ until analysis. Adsorption and non-catalytic (blank) experiments were performed in the absence of SPS and catalyst, respectively. Two model systems of aqueous pollutants were considered, namely: (i) venlafaxine $(250 \mu \mathrm{g}$ $\mathrm{L}^{-1}$ ); and (ii) a mixture containing atenolol, metoprolol, venlafaxine and citalopram $\left(250 \mu \mathrm{g} \mathrm{L}^{-1}\right.$ of each). An additional experiment with metoprolol $\left(250 \mu \mathrm{g} \mathrm{L}^{-1}\right)$ was conducted. Ultrapure (UP), drinking (DW) and surface (SW) water were employed as aqueous matrices in the experiments performed with venlafaxine as model system. Moreover, activated persulfate experiments were performed in the presence of methanol $(\mathrm{MeOH})$ and furfuryl alcohol (FFA). Selected experiments were performed in duplicate. The standard deviation of venlafaxine determination at the end of the experiments was never superior to $2 \%$.

Experiments in continuous (dead-end) mode were performed using the experimental setup depicted in Fig. S4. In this case, a stirred amber glass bottle was loaded with $250 \mathrm{~mL}$ of SW spiked with venlafaxine $(100$ $\left.\mu \mathrm{g} \mathrm{L}^{-1}\right)$. A calculated amount of SPS was then added to obtain the desired concentration of oxidant source $\left(250 \mathrm{mg} \mathrm{L}^{-1}\right)$. After homogenization, the solution was continuously fed to the glass cell containing the CNT@Ni+Fe/ $/ \mathrm{Al}_{2} \mathrm{O}_{3}$-cp-PVDF membrane (effective area $=2.1 \mathrm{~cm}^{2}$ ) at a flow rate of $0.1 \mathrm{~mL} \mathrm{~min}{ }^{-1}$ for $24 \mathrm{~h}$. Samples were periodically withdrawn and kept at $4{ }^{\circ} \mathrm{C}$ until analysis. An adsorption experiment was performed in the absence of SPS.

\subsection{Analytical techniques}

The concentrations of atenolol, metoprolol, venlafaxine and citalopram were determined by ultra-high-performance liquid chromatography (UHPLC) coupled with a fluorescence detector (FD), as previously described (Vieira et al., 2020). A summary of the method parameters is provided in Table S1. Please refer to our previous publication (Vieira et al., 2020) for additional details.

The concentration of SPS was determined by a colourimetric method with N,N-Diethyl-p-plenylenediamine sulphate (DPD), as previously described (Vieira et al., 2020). Dissolved Fe and Ni contents were determined by ICP-OES.

\section{Results and discussion}

\subsection{CNTs characterization}

The four metal catalysts prepared from $\mathrm{Al}_{2} \mathrm{O}_{3}, \mathrm{Ni}, \mathrm{Fe}$ and/or $\mathrm{Al}$ by wetness impregnation and co-precipitation, as described in Section 2.2, were employed in the CVD system (Section 2.3), to promote the growth of four different samples of CNTs from the LDPE feedstock. Synthesis yields in the range 15-20 and 7-16 wt\% (in respect to the mass of LDPE fed to the system) were obtained before and after purification with $\mathrm{H}_{2} \mathrm{SO}_{4}$, respectively. Indeed, the CNTs obtained after the purification step (implemented to remove attached metal species arising from the CVD system) exhibit negligible residual metal contents (in the range 0.1-0.15 wt\%; Table S2). The exception is CNT@Ni/ $\mathrm{Al}_{2} \mathrm{O}_{3}$-wi, which reveals a higher metal content $(1.24 \mathrm{wt} \%)$, corresponding to $\mathrm{Ni}(0.92 \mathrm{wt}$ $\%)$ and $\mathrm{Al}(0.32 \mathrm{wt} \%)$ from the CVD catalyst employed in the synthesis process. The resulting samples of CNTs (i.e., purified) were also characterized by SEM-EDS, TEM, $\mathrm{N}_{2}$ physisorption, acid-base properties, and $\mathrm{pH}_{\mathrm{PZC}}$, and employed in activated persulfate experiments.

SEM micrographs confirm the growth of carbon filaments by CVD over all the prepared metal catalysts (Fig. 1), allowing to conclude about the feasibility of employing LDPE as carbon feedstock in the proposed system. As observed, long carbon filaments are obtained regardless of the catalyst employed. Nevertheless, their properties are expected to depend on the nature of the catalyst (Szabó et al., 2010; Tessonnier et al., 2009). This is the case of the external diameter determined by SEM, which was in the range 4-63 $\mathrm{nm}$. Higher external diameters were obtained in the carbon materials prepared over the two $\mathrm{Ni}+\mathrm{Fe} / \mathrm{Al}_{2} \mathrm{O}_{3}$ supported catalysts (prepared by wetness impregnation and co-precipitation), namely $\mathrm{CNT} @ \mathrm{Ni}+\mathrm{Fe} / \mathrm{Al}_{2} \mathrm{O}_{3}$-wi (in the range 13-63 $\mathrm{nm})$ and $\mathrm{CNT} @ \mathrm{Ni}+\mathrm{Fe} / \mathrm{Al}_{2} \mathrm{O}_{3}-\mathrm{cp}(9-33 \mathrm{~nm})$. On the contrary, materials with lower external diameters were obtained when employing the $\mathrm{Ni} / \mathrm{Al}_{2} \mathrm{O}_{3}$-wi and $\mathrm{Ni}+\mathrm{Fe}+\mathrm{Al}-\mathrm{cp}$ catalysts, namely in $\mathrm{CNT} @ \mathrm{Ni} / \mathrm{Al}_{2} \mathrm{O}_{3}$-wi (8-32 nm) and CNT@Ni+Fe+Al-cp (4-23 nm). Moreover, a wide external diameter distribution range was observed in all the materials. This can be ascribed to the use of thermal decomposition products of LDPE as feedstock for the growth of carbon filaments, since a wide variety of volatile hydrocarbons (e.g., ethene, propene, 1,3-butadiene, methane, 1-butene, n-hexane, isobutene and ethane) are in this way fed to the CVD system (Marcilla et al., 2007).

Fibrous carbon materials, such as CNTs and carbon nanofibers (CNFs), are commonly differentiated by the existence/absence of a hollow cavity within their filaments. Unlike CNTs, CNFs do not have (or have very thin) hollow cavities (Serp and Machado, 2015; Tessonnier et al., 2009). Bearing this in mind, the morphology of the carbon filaments herein prepared from LDPE was characterized by TEM (Fig. 2). Hollow cavities are clearly observed in all materials, regardless of the catalyst employed in the CVD system, allowing to conclude that the proposed methodology is suitable for the synthesis of CNTs. In this case, slightly different internal diameters are observed: $\mathrm{CNT} @ \mathrm{Ni}+\mathrm{Fe} / \mathrm{Al}_{2} \mathrm{O}_{3}$-wi $(8-14 \mathrm{~nm})>\mathrm{CNT} @ \mathrm{Ni}+\mathrm{Fe} / \mathrm{Al}_{2} \mathrm{O}_{3}$-cp $(4-12 \mathrm{~nm})$ $>$ CNT@Ni+Fe+Al-cp (2-12 nm) > CNT@Ni/ $/ \mathrm{Al}_{2} \mathrm{O}_{3}$-wi (4-10 nm). Regarding the morphology, $\mathrm{CNT} @ \mathrm{Ni} / \mathrm{Al}_{2} \mathrm{O}_{3}$-wi are similar to standard

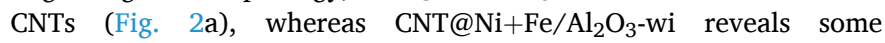
cup-stacked tubes (Fig. 2b), and $\mathrm{CNT} @ \mathrm{Ni}+\mathrm{Fe} / \mathrm{Al}_{2} \mathrm{O}_{3}-\mathrm{cp}$ and $\mathrm{CNT@Ni+Fe+Al-cp} \mathrm{(i.e.,} \mathrm{the} \mathrm{materials} \mathrm{obtained} \mathrm{with} \mathrm{metal} \mathrm{catalysts}$ prepared by co-precipitation) reveal some helical tubes (Fig. $2 \mathrm{c}$ and d, respectively). Moreover, some metal particles encapsulated within the tubes (not removed upon purification with $\mathrm{H}_{2} \mathrm{SO}_{4}$ at $140{ }^{\circ} \mathrm{C}$ ) are observed in all the samples (Fig. 2). This is a common feature, since encapsulation of catalyst nanoparticles typically occurs during CVD (Menezes et al., 2015). The elemental composition of the nanoparticles trapped within the tubes was qualitatively analysed by EDS (Fig. S5). As observed, $\mathrm{Ni}$ and/or $\mathrm{Fe}$, and $\mathrm{Al}$ and $\mathrm{O}$ are the main constituents of the observed nanoparticles, confirming that these arise from the metal catalysts employed in the CVD process.

The textural properties of the CNTs (surface area and porosity) were characterized by $\mathrm{N}_{2}$ physisorption. The adsorption isotherms are shown in Fig. S6, and the corresponding results compiled in Table S3. As observed, CNT@Ni/ $\mathrm{Al}_{2} \mathrm{O}_{3}$-wi possesses the highest $S_{\mathrm{BET}}\left(226 \mathrm{~m}^{2} \mathrm{~g}^{-1}\right)$, whereas similar values are obtained for the CNTs prepared from the three catalysts containing both $\mathrm{Ni}$ and $\mathrm{Fe}\left(S_{\mathrm{BET}}\right.$ in the range $151-155 \mathrm{~m}^{2}$ $\mathrm{g}^{-1}$ ). These values are in line with those commonly determined for CNTs (in the range 10-500 $\mathrm{m}^{2} \mathrm{~g}^{-1}$ ) (Lehman et al., 2011). Indeed, in a previous work of our group, the $S_{\mathrm{BET}}$ of six samples of commercially available CNTs was in the range $41-291 \mathrm{~m}^{2} \mathrm{~g}^{-1}$, and $V_{\text {Total }}$ in the range $0.17-3.2 \mathrm{~cm}^{3} \mathrm{~g}^{-1}$ (Pinho et al., 2015). In the case of the CNTs herein produced from LDPE, $V_{\text {Total }}$ was in the range $0.657-1.042 \mathrm{~cm}^{3} \mathrm{~g}^{-1}$. The highest value was obtained for $\mathrm{CNT} @ \mathrm{Ni}+\mathrm{Fe} / \mathrm{Al}_{2} \mathrm{O}_{3}-\mathrm{cp}$ and the lowest for $\mathrm{CNT} @ \mathrm{Ni}+\mathrm{Fe}+\mathrm{Al}-\mathrm{cp}$. Moreover, it can be observed that, despite having similar values of $S_{\mathrm{BET}}$, the CNTs prepared from the three catalysts containing both $\mathrm{Ni}$ and $\mathrm{Fe}$ have different $V_{\text {Total }}$ (Table S3), allowing to 

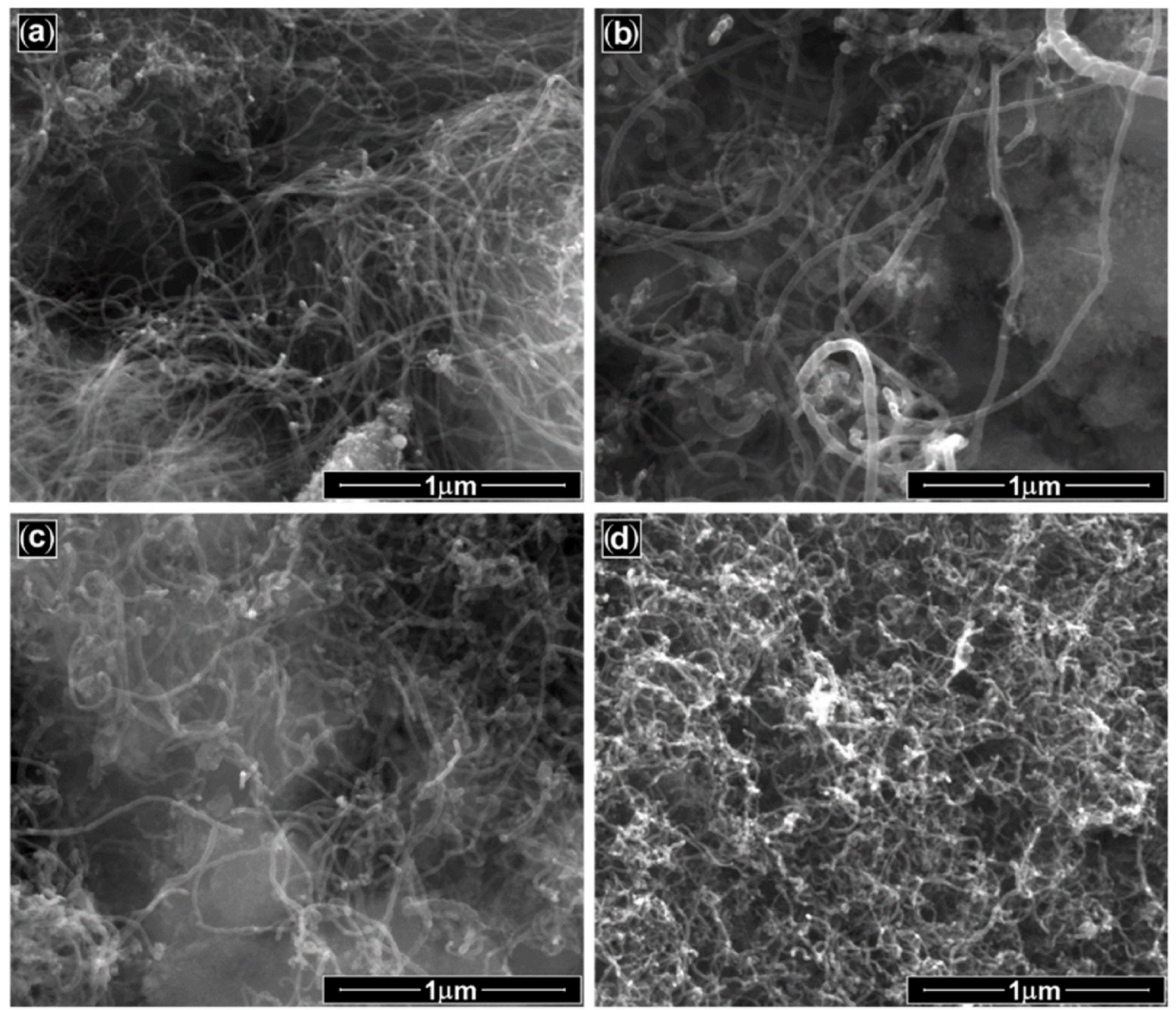

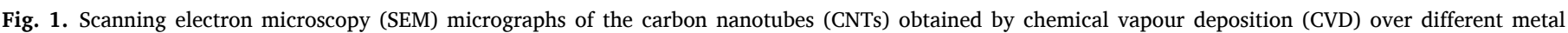

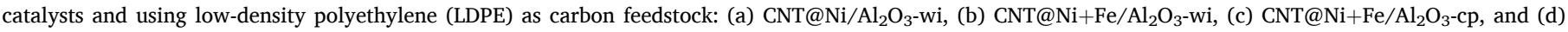
$\mathrm{CNT} @ \mathrm{Ni}+\mathrm{Fe}+\mathrm{Al}-\mathrm{cp}$.

conclude that $\mathrm{CNT} @ \mathrm{Ni}+\mathrm{Fe} / \mathrm{Al}_{2} \mathrm{O}_{3}-\mathrm{cp}$ has the largest pore size, followed by $\mathrm{CNT} @ \mathrm{Ni}+\mathrm{Fe} / \mathrm{Al}_{2} \mathrm{O}_{3}$-wi and $\mathrm{CNT} @ \mathrm{Ni}+\mathrm{Fe}+\mathrm{Al}$-cp.

The acid-base properties and $\mathrm{pH}$ at the point of zero charge $\left(\mathrm{pH}_{\mathrm{PZC}}\right)$ of the CNTs were also determined (Table S3) and briefly discussed (Text S4).

\subsection{Activated persulfate oxidation in batch mode}

The ability of the four powder samples of CNTs prepared from the LDPE feedstock to act as catalysts for activated persulfate oxidation and degradation of organic MPs was first evaluated through experiments performed in batch mode and employing aqueous solutions of venlafaxine $\left(250 \mu \mathrm{g} \mathrm{L}^{-1}\right)$ as model system. The concentration of venlafaxine obtained as function of time, and the removals obtained after $90 \mathrm{~min}$ in adsorption and activated persulfate oxidation experiments are given in Fig. S7 and Fig. 3, respectively. Non-catalytic oxidation promoted by SPS is also given in Fig. 3. In this case, the removal of venlafaxine can be considered negligible, as it amounts to only $\mathrm{ca}$. $8 \%$ of its initial content.

Regarding adsorption removals, the sample of CNTs revealing the best performance is $\mathrm{CNT} @ \mathrm{Ni} / \mathrm{Al}_{2} \mathrm{O}_{3}$-wi (Figs. 3 and S7), which is also the material with the highest $S_{\mathrm{BET}}$ among those under study (Table S3), and the only one prepared from a catalyst that does not contain Fe. On the contrary, the CNTs prepared from the three catalysts containing both $\mathrm{Ni}$ and Fe reveal both similar adsorption capacities (Figs. 3 and S7) and textural properties (Table S3). It is interesting to observe that the removal of venlafaxine undergoes a great increase when SPS is added in the presence of all the CNTs under study (Figs. 3 and S7). These results allow concluding that the four CNTs prepared from the LDPE feedstock are effective catalysts for activated persulfate oxidation and degradation of venlafaxine. Specifically, removals in the range 88-96\% are obtained after $90 \mathrm{~min}$ of reaction. On this regard, the adsorption capacity revealed in Fig. 3 is expected to contribute towards enhancing the performance of the treatment, as it has been shown that the increased local concentration of pollutant molecules nearby surface active sites due to adsorptive interactions enhances the efficiency of activated persulfate oxidation based both on radical (Yin et al., 2018) or non-radical (Chu et al., 2019) mechanisms. Nevertheless, the difference of venlafaxine removal due to SPS addition $\left(d_{\text {Removal }}\right.$, i.e., the increase of pollutant removal obtained in the activated persulfate oxidation experiments compared to that obtained by adsorption) points out a catalyst with apparently higher activity (Fig. 3). This corresponds to the maximum value of $d_{\text {Removal, }}$, obtained when employing CNT@Ni+Fe $/ \mathrm{Al}_{2} \mathrm{O}_{3}$-cp. This enhanced performance for persulfate activation and degradation of venlafaxine becomes even more interesting when the residual metal content of the CNTs samples (Table S2) are compared, since CNT@Ni+Fe/ $\mathrm{Al}_{2} \mathrm{O}_{3}-\mathrm{cp}$ is one of the samples with the lowest content of metal species after the purification step with $\mathrm{H}_{2} \mathrm{SO}_{4}$ employed at the end of the synthesis procedure, corresponding to only $0.1 \mathrm{wt} \%$. 

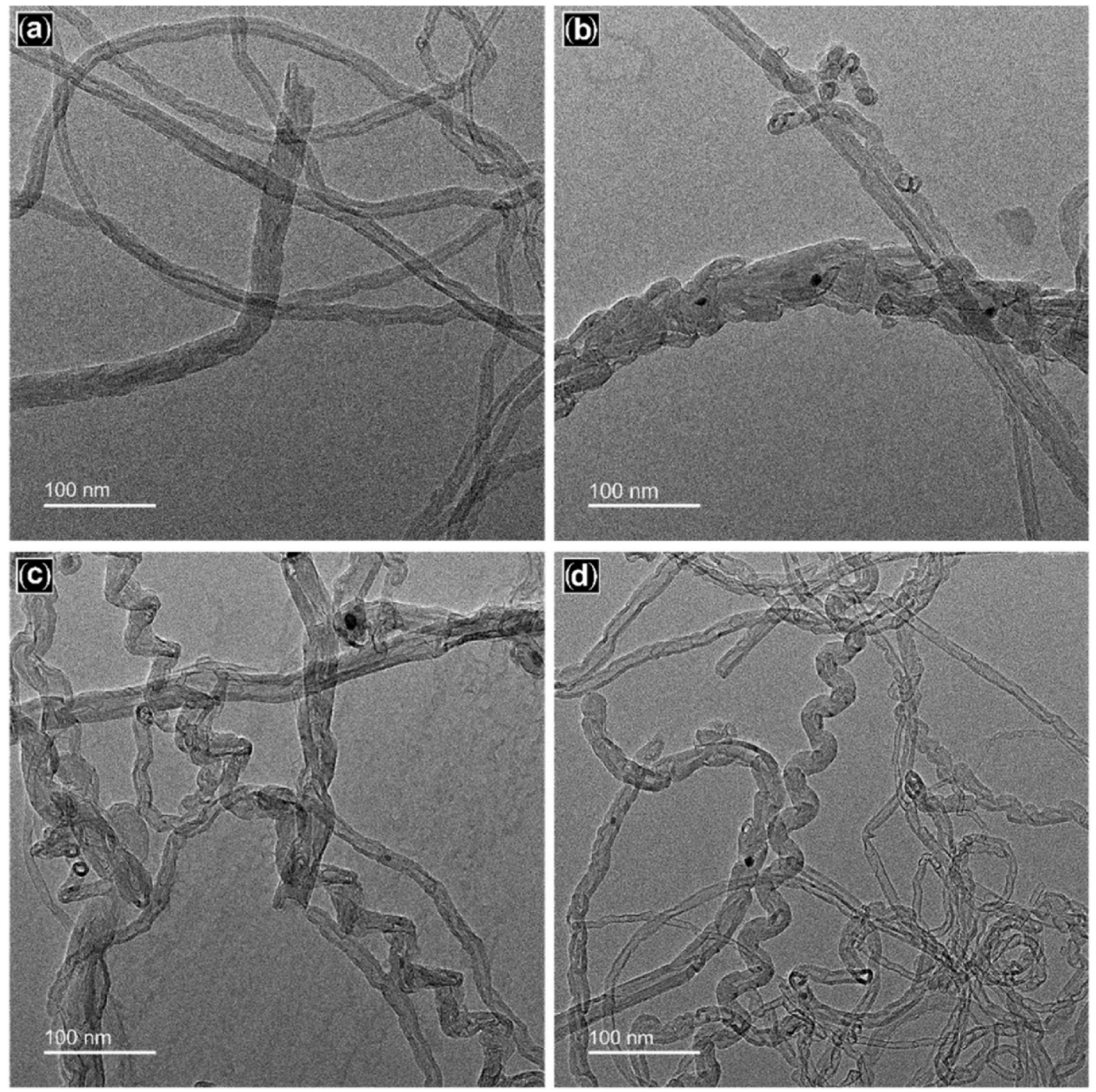

Fig. 2. Transmission electron microscopy (TEM) micrographs of the carbon nanotubes (CNTs) obtained by chemical vapour deposition (CVD) over different metal catalysts and using low-density polyethylene (LDPE) as carbon feedstock: (a) CNT@Ni/ $\mathrm{Al}_{2} \mathrm{O}_{3}$-wi, (b) $\mathrm{CNT} @ \mathrm{Ni}+\mathrm{Fe} / \mathrm{Al}_{2} \mathrm{O}_{3}-\mathrm{wi}$, (c) $\mathrm{CNT} @ \mathrm{Ni}+\mathrm{Fe} / \mathrm{Al}_{2} \mathrm{O}_{3}-\mathrm{cp}$, and (d) CNT@Ni+Fe+Al-cp.

It is noteworthy that the catalyst with the lowest activity for persulfate oxidation is CNT@Ni/ $\mathrm{Al}_{2} \mathrm{O}_{3}$-wi, as shown by the lowest value of $d_{\text {Removal }}$ (Fig. 3). This can be partially explained by the lack of residual Fe within the CNTs (Table S2), which is a known persulfate activator (Oyekunle et al., 2021). Indeed, the sample with the second lowest value of $d_{\text {Removal }}$ is CNT@Ni+Fe/ $/ \mathrm{Al}_{2} \mathrm{O}_{3}$-wi, which is also the sample with the second lowest amount of residual Fe in its structure (Table S2). Therefore, these results suggest that, despite being present in residual amounts (Table S2), metal particles (not completely removed during the purification step; Fig. 2) still contribute towards heterogeneous persulfate activation and can be responsible for the slightly different catalytic performances of the samples under study.

The concentration of venlafaxine obtained as function of time in adsorption and activated persulfate oxidation experiments performed with $\mathrm{CNT} @ \mathrm{Ni}+\mathrm{Fe} / \mathrm{Al}_{2} \mathrm{O}_{3}$-cp are detailed in Fig. S8, together with the non-catalytic removals promoted by SPS only. In the catalytic experiment, ca. $95 \%$ of venlafaxine removal is achieved upon $90 \mathrm{~min}$ of activated persulfate oxidation, corresponding to a pollutant mass removal rate of $3.17 \mathrm{mg} \mathrm{g}^{-1} \mathrm{~h}^{-1}$ (determined as described in Text S5 and Eq. S1). SPS consumption during this treatment process amounts to $23.7 \%$ of its initial content (as determined at the end of the activated persulfate oxidation run). These results confirm the ability of $\mathrm{CNT} @ \mathrm{Ni}+\mathrm{Fe} / \mathrm{Al}_{2} \mathrm{O}_{3}-$ $\mathrm{cp}$ to activate SPS. Moreover, despite having negligible metal content (Table S2), possible metal leaching from CNT@Ni+Fe/ $\mathrm{Al}_{2} \mathrm{O}_{3}$-cp to the treated water was determined by ICP-OES at the end of the activated persulfate oxidation run. The leaching of $\mathrm{Fe}$ and $\mathrm{Ni}$ to the treated water was 2.55 and $0.74 \mu \mathrm{g} \mathrm{L}^{-1}$, respectively, allowing to conclude about the predominant role of heterogeneous activated persulfate oxidation promoted by $\mathrm{CNT} @ \mathrm{Ni}+\mathrm{Fe} / \mathrm{Al}_{2} \mathrm{O}_{3}$-cp. Indeed, these concentrations are $c a$. 80- and 30-fold below the European limits for water intended for human consumption as defined in Directive (EU) 2020/2184 of the European Parliament and of the Council of December 16, 2020 (200 and $20 \mu \mathrm{g} \mathrm{L}^{-1}$, for $\mathrm{Fe}$ and $\mathrm{Ni}$, respectively), and therefore can be held negligible. Regarding the metal loss of the catalyst itself, these values correspond to 8.5 and $7.4 \%$ of the $\mathrm{Fe}$ and $\mathrm{Ni}$ content of $\mathrm{CNT} @ \mathrm{Ni}+\mathrm{Fe} / \mathrm{Al}_{2} \mathrm{O}_{3}-\mathrm{cp}$ (Table S2), respectively. These apparently high values are explained by 


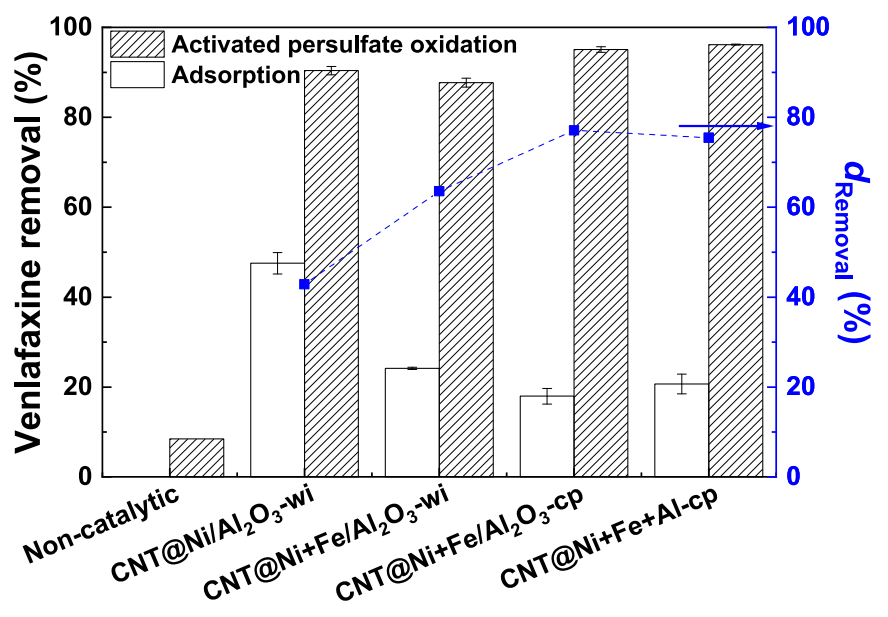

Fig. 3. Removal of venlafaxine in liquid phase after $90 \mathrm{~min}$, in adsorption and activated persulfate oxidation experiments (bars/left axis) performed in ultrapure (UP) water, and respective difference due to the addition of SPS [ $d_{\text {Removal }}$ (squares/right axis)]. Experiments performed in batch mode, with [venlafaxine $]_{0}=250 \mu \mathrm{g} \mathrm{L}^{-1}$, [catalyst/adsorbent] $=0.05 \mathrm{~g} \mathrm{~L}^{-1}$, [SPS $]_{0}=250 \mathrm{mg} \mathrm{L}^{-1}$, $\mathrm{pH}_{0}=5.9$ (inherent $\mathrm{pH}$ ), and $\mathrm{T}=22 \pm 2{ }^{\circ} \mathrm{C}$. Experiments performed in duplicate.

the negligible residual content of $\mathrm{Fe}(0.06 \mathrm{wt} \%)$ and $\mathrm{Ni}(0.02 \mathrm{wt} \%)$ in the pristine catalyst.

The influence of catalyst dosage on the removal of venlafaxine was briefly investigated (Fig. S9). As observed, venlafaxine is completely removed when the concentration of CNTs is increased to $0.25 \mathrm{~g} \mathrm{~L}^{-1}$ (Fig. S9b). However, this enhanced pollutant removal can be explained by the higher contribution of the adsorption component. Therefore, a catalyst/adsorbent concentration of $0.05 \mathrm{~g} \mathrm{~L}^{-1}$ was selected for the subsequent studies performed in batch mode, namely regarding the simultaneous removal of four MPs. An aqueous solution containing atenolol, metoprolol and citalopram $\left(250 \mu \mathrm{g} \mathrm{L}{ }^{-1}\right.$ of each) was used for that purpose. As observed (Fig. S10), CNT@Ni+Fe $/ \mathrm{Al}_{2} \mathrm{O}_{3}-\mathrm{cp}$ also performed better under these conditions, promoting higher removals of atenolol, venlafaxine and citalopram, and similar removals of metoprolol. Accordingly, the adsorption and activated persulfate oxidation experiments performed with $\mathrm{CNT} @ \mathrm{Ni}+\mathrm{Fe} / \mathrm{Al}_{2} \mathrm{O}_{3}-\mathrm{cp}$ are detailed in Figs. S11a and b, respectively. As observed, the removal of the organic MPs was higher in the activated persulfate oxidation run, but particularly for citalopram and venlafaxine, allowing to conclude that $\mathrm{CNT} @ \mathrm{Ni}+\mathrm{Fe} / \mathrm{Al}_{2} \mathrm{O}_{3}$-cp is an active catalyst for activated persulfate oxidation of these organic MPs. Nevertheless, after ca. 15 min of reaction, the concentration of atenolol increased slightly, and was kept above its initial concentration (i.e., $C / C_{0}>1$ ) for at least $45 \mathrm{~min}$, period after which it decreased again (Fig. S11b). This is an uncommon observation; thus, although studying the MPs conversion pathway is not a goal of this study, additional investigations were conducted to clarify this trend. Upon carefully analysing the chemical structure of the pollutants under study (Table S4), the seemingly most plausible explanation is the conversion of metoprolol into atenolol. Bearing this in mind, an additional activated persulfate oxidation experiment was performed with an aqueous solution containing metoprolol only. As observed, atenolol is indeed formed as metoprolol is degraded under these conditions (Fig. S12). Since the exact mechanism behind the conversion of metoprolol into atenolol is still unknown, the results herein observed should prompt additional studies on the topic.

The influence of the water matrix on venlafaxine removal by activated persulfate oxidation promoted by $\mathrm{CNT} @ \mathrm{Ni}+\mathrm{Fe} / \mathrm{Al}_{2} \mathrm{O}_{3}-\mathrm{cp}$ was also studied (Fig. 4). For comparison purposes, the removals obtained by adsorption and non-catalytic conversion promoted by SPS are shown in Fig. S13. As observed in Fig. 4, the efficiency of the activated persulfate oxidation process increases when the venlafaxine solutions are prepared

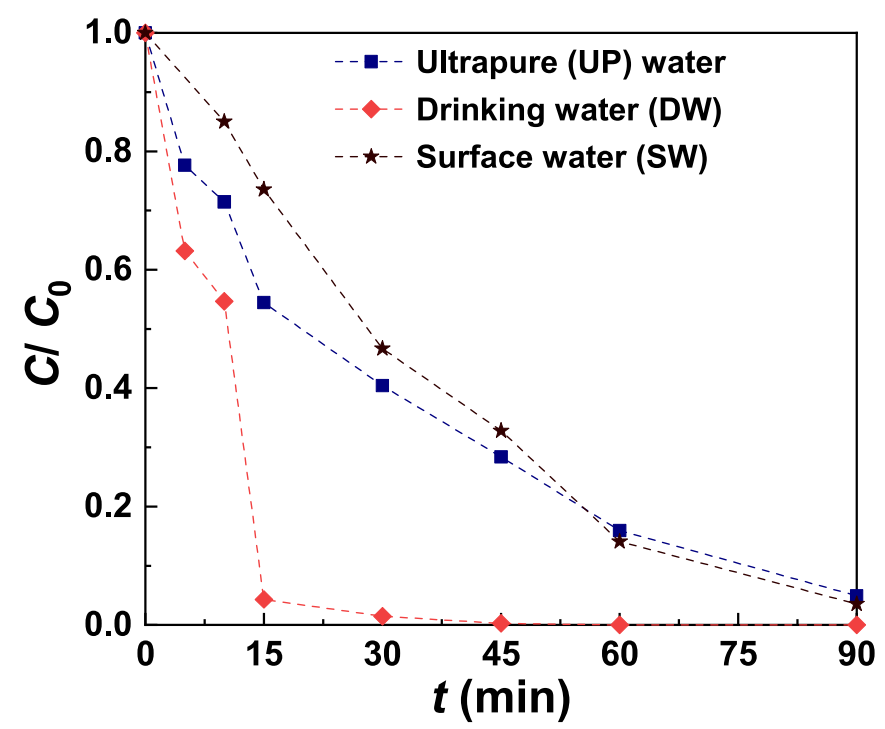

Fig. 4. Effect of water matrix on the removal of venlafaxine by activated persulfate oxidation in the presence of $\mathrm{CNT} @ \mathrm{Ni}+\mathrm{Fe} / \mathrm{Al}_{2} \mathrm{O}_{3}$-cp. Experiments performed in batch mode, with [venlafaxine $]_{0}=250 \mu \mathrm{g} \mathrm{L}{ }^{-1}$, [CNT@Ni+Fe/ $\mathrm{Al}_{2} \mathrm{O}_{3}$ $\mathrm{cp}]=0.05 \mathrm{~g} \mathrm{~L}^{-1}$, [SPS $]_{0}=250 \mathrm{mg} \mathrm{L}^{-1}, \mathrm{pH}_{0}=5.9,6.8$ and 7.5 (inherent $\mathrm{pH}$ of UP water, DW and SW, respectively), and $T=22 \pm 2{ }^{\circ} \mathrm{C}$.

in DW instead of UP water, whereas employing SW has a negligible effect. Several ions naturally occurring in environmental water matrices (e.g., chloride and bicarbonate ions) are known to affect the performance of activated persulfate oxidation. On that regard, both beneficial and detrimental effects have been reported (Outsiou et al., 2017; Bennedsen et al., 2012; Fang et al., 2012; Lutze et al., 2015; Matzek and Carter, 2016). Therefore, the effect of environmentally relevant concentrations of chloride and bicarbonate ions on the removal of venlafaxine was studied together with the influence of the initial solution $\mathrm{pH}$ (Fig. S14). The corresponding results are discussed in Text S6, considering the second order reaction rate constants $(k)$ of several inorganic radicals towards venlafaxine (Table S5). Briefly, the enhanced removal of venlafaxine obtained in DW seems to be related with the formation of carbonate radicals from the reaction of bicarbonates with sulphate and/or hydroxyl radicals; whereas the (apparently unaffected) removal of venlafaxine obtained in SW can be ascribed to two opposite effects: the positive contribution arising from the presence of bicarbonates (Fig. S14a), and the negative contributions resulting from the higher $\mathrm{pH}$ (Fig. S14b) and the presence of dissolved organic matter in this matrix.

The solution $\mathrm{pH}$ was also monitored during the experiments depicted in Fig. 4. In UP water, the solution $\mathrm{pH}$ dropped from 5.9 (in the initial solution) to 4.0 (in the treated water), suggesting that the oxidation of venlafaxine leads to the opening of its aromatic ring and the subsequent formation of acidic by-products, such as low-molecular weight carboxylic acids. On the contrary, the solution $\mathrm{pH}$ dropped slightly during the experiments with DW (from 6.8 to 6.2) and SW (from 7.5 to 7.3 ), which can be explained by the natural buffer capacity these water matrices. Moreover, an experiment performed under intensified conditions confirmed that venlafaxine is partially mineralized during the treatment process (Text S7).

Scavenging tests with methanol $(\mathrm{MeOH})$ and furfuryl alcohol (FFA) were then carried out to provide preliminary insights on the reaction mechanisms involved in the activated persulfate oxidation of venlafaxine promoted by $\mathrm{CNT} @ \mathrm{Ni}+\mathrm{Fe} / \mathrm{Al}_{2} \mathrm{O}_{3}$-cp (Fig. S15). These results were discussed based on findings reported in the literature (Text S8), leading to the proposal of a broad reaction mechanism based on both radical and non-radical pathways (Fig. S16). 


\subsection{Activated persulfate oxidation in continuous mode: a proof of concept}

Considering the catalytic activity revealed by $\mathrm{CNT} @ \mathrm{Ni}+\mathrm{Fe} / \mathrm{Al}_{2} \mathrm{O}_{3}-\mathrm{cp}$ in the activated persulfate oxidation experiments performed in batch mode, additional experiments were performed in continuous mode of operation. For that purpose, a carbon-based catalytic membrane was prepared by including CNT@Ni+Fe $/ \mathrm{Al}_{2} \mathrm{O}_{3}$-cp within a PVDF matrix, through a fabrication methodology previously reported by our group (Vieira et al., 2020), and placed in a glass cell to which a pollutant solution was fed under constant flow conditions (Miller et al., 2014). The resulting composite membrane (CNT@Ni+Fe/ $/ \mathrm{Al}_{2} \mathrm{O}_{3}-\mathrm{cp}-\mathrm{PVDF}$ ) is able to stand alone, i.e., do not need a support (Fig. S3), and is structurally stable under the operating conditions considered in this study. Moreover, the morphology of the composite membrane was characterized by SEM (Fig. 5). The typical external surface pores of polymeric membranes can be observed in the top view of CNT@Ni+Fe/ $/ \mathrm{Al}_{2} \mathrm{O}_{3}$-cp-PVDF (Fig. 5a) (Liu et al., 2011; Vieira et al., 2020). Indeed, these are similar to those observed in a PVDF membrane prepared in the absence of active catalytic phase in our previous work (Fig. S17b). On the contrary, the typical cross-sectional channels observed for the polymeric membranes in the absence of CNTs (Fig. S17d) are not verified in the SEM images of $\mathrm{CNT} @ \mathrm{Ni}+\mathrm{Fe} / \mathrm{Al}_{2} \mathrm{O}_{3}$-cp-PVDF, since aggregates of $\mathrm{CNT} @ \mathrm{Ni}+\mathrm{Fe} / \mathrm{Al}_{2} \mathrm{O}_{3}-\mathrm{cp}$ are uniformly distributed within the PVDF matrix (Fig. 5b and c). The preferential embedding of CNT@Ni+Fe/ $/ \mathrm{Al}_{2} \mathrm{O}_{3}-\mathrm{cp}$ within the PVDF matrix of the composite membrane (rather than on its external surface) is also clearly observed in the inset of Fig. 5a. In addition, the thickness of the $\mathrm{CNT} @ \mathrm{Ni}+\mathrm{Fe} / \mathrm{Al}_{2} \mathrm{O}_{3}$-cp-PVDF membrane was estimated as $205 \pm 11 \mu \mathrm{m}$ (Fig. 5b).

The CNT@Ni+Fe/ $/ \mathrm{Al}_{2} \mathrm{O}_{3}$-cp-PVDF membrane was also characterized by TGA (Fig. S18). Overall, the composite membrane reveals thermal stability until $c a .300{ }^{\circ} \mathrm{C}$. Afterwards, the weight loss goes through a maximum at $488^{\circ} \mathrm{C}$, corresponding to the sharpest peak observed in the DTGA profile (Fig. S18b). This can be ascribed to the decomposition of PVDF (Silva et al., 2015). Moreover, a less pronounced peak is observed at ca. $390{ }^{\circ} \mathrm{C}$, which is due to the decomposition of PVP (Silva et al., 2015).

The experimental setup used to conduct the experiments in continuous mode is depicted in Fig. S4. Nor the fabrication methodology (Section 2.4 and text S3), nor the operating conditions were optimized, since the goal is to provide an early proof of concept that this material can be applied for the removal of venlafaxine $\left(100 \mu \mathrm{g} \mathrm{L}^{-1}\right)$ in continuous mode during a longer period $(24 \mathrm{~h})$, considering the same dosage of SPS as in batch experiments, and employing SW as water matrix. Thus, additional studies may eventually be focused on optimizing this approach.

Adsorption removals were studied first (Fig. 6a). As observed, the venlafaxine removal reached $c a .30 \%$ at the beginning of the adsorption experiment, then decreasing as the membrane becomes increasingly saturated. On the contrary, a sharp decrease of the venlafaxine concentration is observed when SPS is added (Fig. 6b). In this case,
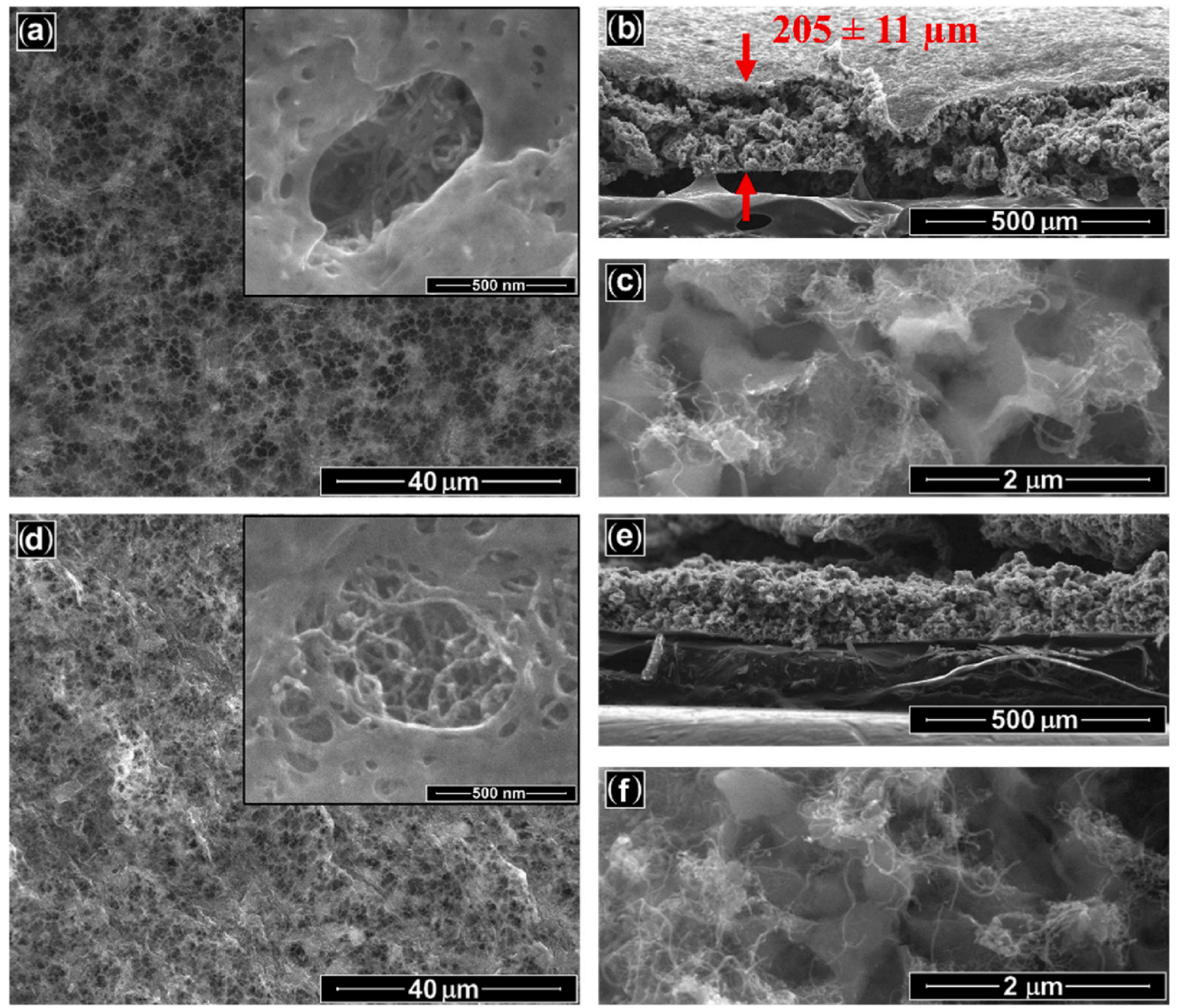

Fig. 5. Scanning electron microscopy (SEM) micrographs of (a, b, c) pristine and (d, e, f) used CNT@Ni+Fe/ $\mathrm{Al}_{2} \mathrm{O}_{3}$-cp-PVDF membranes. (a, d) top and (b, c, e, f) cross-sectional views. 

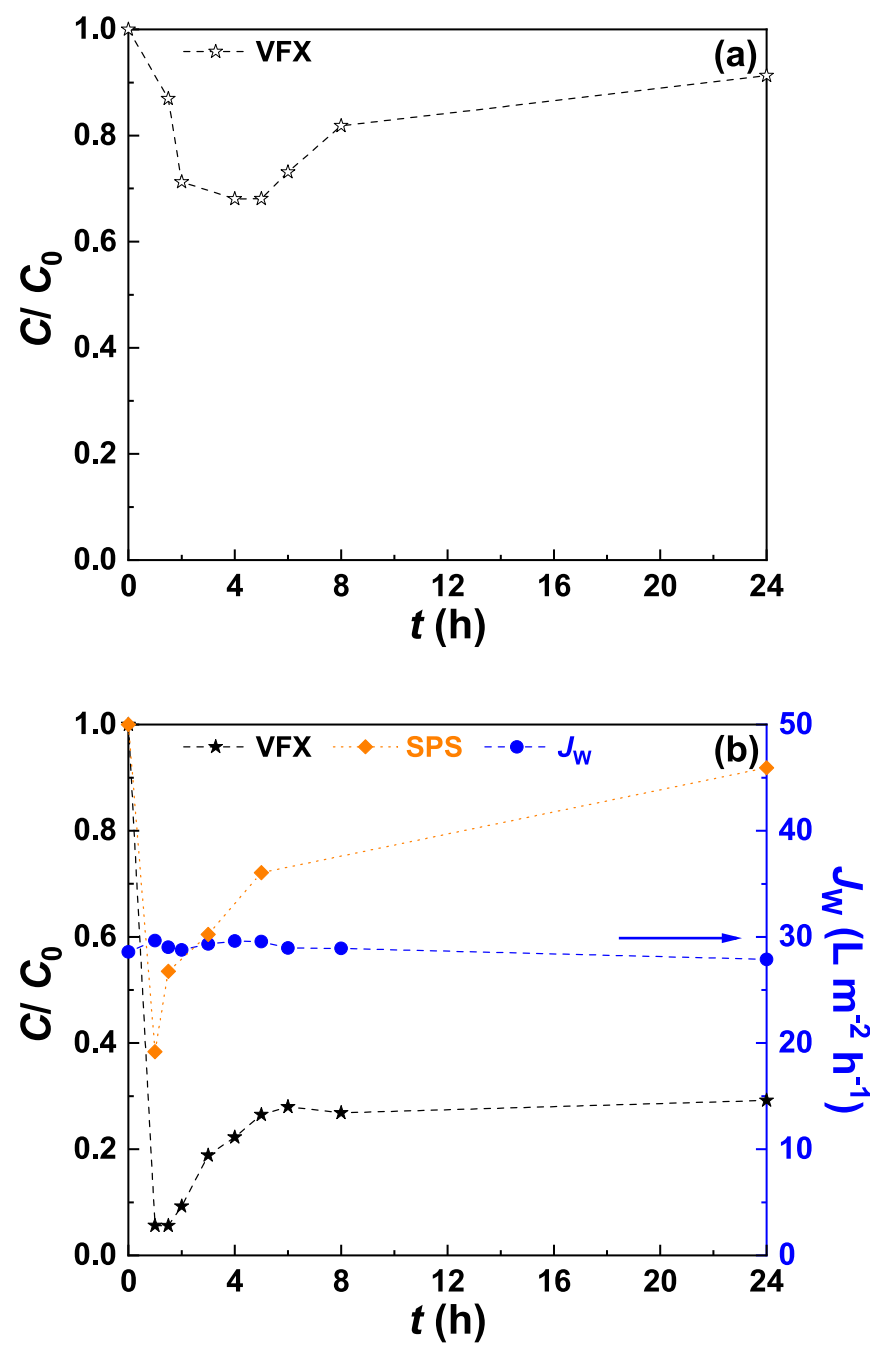

Fig. 6. Normalized concentration of venlafaxine obtained as function of time in (a) adsorption and (b) activated persulfate oxidation experiments performed in surface water (SW), with composite CNT@Ni+Fe/ $\mathrm{Al}_{2} \mathrm{O}_{3}$-cp-PVDF membranes. Water permeate flux $(\mathrm{Jw})$ and conversion of SPS are also shown in (b). Experiments performed in continuous mode, with [venlafaxine] $]_{0}=100 \mu \mathrm{g} \mathrm{L}^{-1}$, $[\mathrm{SPS}]_{0}=250 \mathrm{mg} \mathrm{L}^{-1}, \mathrm{pH}_{0}=7.5$ (inherent $\mathrm{pH}$ ), $Q=0.1 \mathrm{~mL} \mathrm{~min}^{-1}$, and $T=22$ $\pm 2{ }^{\circ} \mathrm{C}$.

venlafaxine removals up to $c a$. $95 \%$ are observed within the first $1.5 \mathrm{~h}$ of operation in continuous mode, the performance of the process then slightly decreasing and being kept nearly constant (steady state) for the remaining period 5-24 h. For instance, venlafaxine removal is still high at the end of the experiment ( $c a .71 \%$ of its initial content), corresponding to a pollutant mass removal rate of $1.97 \mathrm{mg} \mathrm{m}^{-2} \mathrm{~h}^{-1}$ (determined as described in Text S5 and Eq. S3). These results allow concluding about the stability of the $\mathrm{CNT} @ \mathrm{Ni}+\mathrm{Fe} / \mathrm{Al}_{2} \mathrm{O}_{3}$-cp catalytic active phase (within the composite membrane) for up to $24 \mathrm{~h}$ of continuous operation. Moreover, SPS consumption was observed during the entire experiment (Fig. 6b), allowing to conclude that the composite polymeric membrane can promote the decomposition of SPS. Water permeate flux ( $J_{\mathrm{W}}$; determined as described in Text S5 and Eq. S2) was also monitored. As observed, $J_{\mathrm{W}}$ is nearly constant during the activated persulfate oxidation experiment (Fig. 6b), allowing to conclude that membrane fouling is apparently negligible. This high resistance to fouling can be explained both by the antifouling properties of carbon materials (Ayyaru and Ahn, 2017; Zhang et al., 2013) and the size of the largest pore of the $\mathrm{CNT} @ \mathrm{Ni}+\mathrm{Fe} / \mathrm{Al}_{2} \mathrm{O}_{3}$-cp-PVDF membrane that was developed ( $4.96 \mu \mathrm{m}$; as determined by the bubble-point method). This value is far above the size of the venlafaxine molecule and the dissolved solids $(<0.45 \mu \mathrm{m})$ typically found in SW, but also above most of the suspended solids that can be found in the same matrix. The eco and phytotoxicity of the treated water collected during the $24 \mathrm{~h}$ of operation in continuous mode were also evaluated (Text S9, Table S6 and Fig. S19). It was concluded that the treated water does not exhibit toxicity and thus seems to be safe for reuse and/or discharge in aquatic compartments. Taking all into consideration, it can be concluded that the composite polymeric membrane is effective for activated persulfate oxidation in continuous mode of operation and degradation of venlafaxine in SW.

SEM micrographs taken on the CNT@Ni+Fe $/ \mathrm{Al}_{2} \mathrm{O}_{3}$-cp-PVDF membrane collected at the end of the experiment depicted in Fig. $6 \mathrm{~b}$ reveal that its morphology (Fig. 5d, e, f) is not significantly affected by the catalytic process performed during $24 \mathrm{~h}$. Nevertheless, the surface roughness of the used membrane (Fig. 5d) seems to be slightly higher than that of the pristine membrane (Fig. 5a). Similar conclusions can be withdrawn by TGA (Fig. S18). After $24 \mathrm{~h}$ of continuous operation, the $\mathrm{CNT} @ \mathrm{Ni}+\mathrm{Fe} / \mathrm{Al}_{2} \mathrm{O}_{3}$-cp-PVDF membrane reveals a similar thermal decomposition profile when compared to the pristine membrane, confirming that its structure is not affected during the catalytic process. Nevertheless, a closer analysis of the TGA curve in the range $250-280{ }^{\circ} \mathrm{C}$ (inset of Fig. S18), i.e., the temperature at which the venlafaxine salt used in this study completely volatilises (Roy et al., 2005), suggests that the membrane becomes partially loaded (possibly by venlafaxine itself and/or its degradation by-products, SPS and/or natural constituents of SW). Specifically, the amount of these deposits on the membrane amounts to $0.31 \mathrm{wt} \%$ of the membrane (13.2 mg; Table S7), corresponding to $40.9 \mu \mathrm{g}$ only. Despite being low, these deposits may be responsible for the partial loss of the ability to decompose persulfate observed in Fig. 6b. Nevertheless, it should be noted that no decline of catalytic activity regarding degradation of venlafaxine was observed after achieving the steady state at $c a .5 \mathrm{~h}$ (Fig. 6b). Bearing this in mind, it can be concluded that the stable catalytic activity and the robustness of the membrane (including the external surface pores and cross-sectional channels, as shown by SEM and TGA), both contribute towards the high resistance to fouling observed in Fig. $6 \mathrm{~b}$.

The results herein reported were compared to those obtained in previous studies on the application of carbon-based catalytic membranes without added metals for activation of persulfates and degradation of organic pollutants in continuous mode of operation (Table S7). Moreover, a detailed discussion on previous literature on this topic is provided in Text S10. Briefly, only 2 out of the 7 previous studies summarized in Table S7 report the application of environmentally relevant pollutant concentrations and water matrices, such as surface water (Qian et al., 2021; Vieira et al., 2020). The pollutant mass removal rate obtained in this study $\left(1.97 \mathrm{mg} \mathrm{m}^{-2} \mathrm{~h}^{-1}\right.$; after $\left.24 \mathrm{~h}\right)$ is higher than that obtained in the only previous study in which composite polymeric membranes were employed (Vieira et al., 2020). The pollutant mass removal rate obtained in the study performed by Qian et al. (2021) $\left(7.32 \mathrm{mg} \mathrm{m}^{-2} \mathrm{~h}^{-1}\right.$; after $24 \mathrm{~h}$ ) is higher. However, those results were obtained with membranes fabricated by simple vacuum filtration of $20.8 \mathrm{mg}$ of carbon catalytic active phase into a nylon substrate (which are typically less resistant to disintegration upon continuous operation), whereas the results reported in the present study were obtained with composite polymeric membranes (which are more robust) containing only ca. $0.7 \mathrm{mg}$ of carbon catalytic active phase (corresponding to $3.2 \mathrm{wt}$ $\%$ of the membrane).

\section{Conclusions}

Low-density polyethylene (LDPE) was a suitable carbon feedstock for the growth of carbon nanotubes (CNTs) by chemical vapour deposition (CVD) using four different metal-based catalysts $\left(\mathrm{Al}_{2} \mathrm{O}_{3}, \mathrm{Ni}, \mathrm{Fe}\right.$ and/or $\mathrm{Al})$. For the first time, LDPE derived CNTs were demonstrated to be active catalysts for persulfate activation and degradation of organic 
micropollutants. The best performing CNTs in batch mode of operation (CNT@Ni+Fe/ $/ \mathrm{Al}_{2} \mathrm{O}_{3}$-cp) were also active for the removal of venlafaxine as model compound in relevant environmental water matrices, such as surface water. These CNTs were used to fabricate a composite polymeric membrane with poly(vinylidene fluoride) - PVDF that was effective for venlafaxine removal in continuous mode of operation using surface water. Moreover, the treated water did not reveal toxicity and thus seems to be suitable for reuse and/or discharge in the natural media.

\section{Credit author statement}

Rui S. Ribeiro: Conceptualization, Methodology, Investigation, Formal analysis, Writing - original draft, Supervision; Octávia Vieira: Investigation, Formal analysis; Rita Fernandes: Investigation, Formal analysis; Fernanda F. Roman: Investigation, Formal analysis; Jose L. Diaz de Tuesta: Methodology, Writing - review \& editing, Supervision, Project administration, Funding acquisition; Adrián M.T. Silva: Conceptualization, Writing - review \& editing, Supervision, Project administration, Funding acquisition; Helder T. Gomes: Conceptualization, Writing - review \& editing, Supervision, Project administration, Funding acquisition.

\section{Declaration of competing interest}

The authors declare that they have no known competing financial interests or personal relationships that could have appeared to influence the work reported in this paper.

\section{Acknowledgments}

This work was financially supported by project POCI-01-0145FEDER-031439 (PLASTIC TO FUEL\&MAT) funded by FEDER funds through COMPETE2020 - Programa Operacional Competitividade e Internacionalização (POCI), and by national funds (PIDDAC) through FCT/MCTES. We would also like to thank the scientific collaboration under Base-UIDB/50020/2020 and Programmatic-UIDP/50020/2020 Funding of LSRE-LCM - funded by national funds through FCT/MCTES (PIDDAC), Base Funding UIDB/00690/2020 of the Centro de Investigação de Montanha (CIMO) - funded by national funds through FCT/ MCTES (PIDDAC), and projects NORTE-01-0145-FEDER-031049 (InSpeCt - PTDC/EAM-AMB/31049/2017) funded by FEDER funds through NORTE 2020 - Programa Operacional Regional do NORTE, and by national funds (PIDDAC) through FCT/MCTES, and NORTE-01-0145FEDER-000069 (Healthy Waters) funded by NORTE 2020 under the PORTUGAL 2020 Partnership Agreement through FEDER. Fernanda Fontana Roman also thanks to the FCT for the individual research grant SFRH/BD/143224/2019. Technical assistance with SEM analysis is gratefully acknowledged to CEMUP team.

\section{Appendix A. Supplementary data}

Supplementary data to this article can be found online at https://doi. org/10.1016/j.jenvman.2022.114622.

\section{References}

Ayyaru, S., Ahn, Y.-H., 2017. Application of sulfonic acid group functionalized graphene oxide to improve hydrophilicity, permeability, and antifouling of PVDF nanocomposite ultrafiltration membranes. J. Membr. Sci. 525, 210-219. https://doi. org/10.1016/j.memsci.2016.10.048.

Barbosa, M.O., Lado Ribeiro, A.R., Ratola, N., Hain, E., Homem, V., Pereira, M.F.R., Blaney, L., Silva, A.M.T., 2018. Spatial and seasonal occurrence of micropollutants in four Portuguese rivers and a case study for fluorescence excitation-emission matrices. Sci. Total Environ. 644, 1128-1140. https://doi.org/10.1016/j. scitotenv.2018.06.355.

Bazargan, A., McKay, G., 2012. A review - synthesis of carbon nanotubes from plastic wastes. Chem. Eng. J. 195-196, 377-391. https://doi.org/10.1016/j. cej.2012.03.077.
Bennedsen, L.R., Muff, J., Søgaard, E.G., 2012. Influence of chloride and carbonates on the reactivity of activated persulfate. Chemosphere 86, 1092-1097. https://doi.org/ 10.1016/j.chemosphere.2011.12.011.

Borsodi, N., Szentes, A., Miskolczi, N., Wu, C., Liu, X., 2016. Carbon nanotubes synthetized from gaseous products of waste polymer pyrolysis and their application. J. Anal. Appl. Pyrolysis 120, 304-313. https://doi.org/10.1016/j.jaap.2016.05.018.

Cai, N., Xia, S., Zhang, X., Meng, Z., Bartocci, P., Fantozzi, F., Chen, Y., Chen, H., Williams, P.T., Yang, H., 2020a. Preparation of iron- and nitrogen-codoped carbon nanotubes from waste plastics pyrolysis for the oxygen reduction reaction. ChemSusChem 13, 938-944. https://doi.org/10.1002/cssc.201903293.

Cai, N., Yang, H., Zhang, X., Xia, S., Yao, D., Bartocci, P., Fantozzi, F., Chen, Y., Chen, H., Williams, P.T., 2020b. Bimetallic carbon nanotube encapsulated Fe-Ni catalysts from fast pyrolysis of waste plastics and their oxygen reduction properties. Waste Manag. 109, 119-126. https://doi.org/10.1016/j.wasman.2020.05.003.

Chen, X., Oh, W.-D., Lim, T.-T., 2018. Graphene- and CNTs-based carbocatalysts in persulfates activation: material design and catalytic mechanisms. Chem. Eng. J. 354, 941-976. https://doi.org/10.1016/j.cej.2018.08.049.

Chu, C., Yang, J., Huang, D., Li, J., Wang, A., Alvarez, P.J.J., Kim, J.-H., 2019. Cooperative pollutant adsorption and persulfate-driven oxidation on hierarchically ordered porous carbon. Environ. Sci. Technol. 53, 10352-10360. https://doi.org/ 10.1021/acs.est.9b03067.

Comission, E.U., 2020. Commission Implementing Decision (EU) 2020/1161 of 4 August 2020 Establishing a Watch List of Substances for Union-wide Monitoring in the Field of Water Policy Pursuant to Directive 2008/105/EC of the European Parliament and of the Council. Official Journal of the European Union. https://eur-lex.europa.eu/e li/dec impl/2020/1161/oj.

Deokar, S.K., Bajad, G.S., Bhonde, P., Vijayakumar, R.P., Mandavgane, S.A., 2017. Adsorptive removal of diuron herbicide on carbon nanotubes synthesized from plastic waste. J. Polym. Environ. 25, 165-175. https://doi.org/10.1007/s10924016-0794-3.

Diaz de Tuesta, J.L., Machado, B.F., Serp, P., Silva, A.M.T., Faria, J.L., Gomes, H.T., 2020. Janus amphiphilic carbon nanotubes as pickering interfacial catalysts for the treatment of oily wastewater by selective oxidation with hydrogen peroxide. Catal. Today 356, 205-215. https://doi.org/10.1016/j.cattod.2019.07.012.

Duan, X., Sun, H., Wang, S., 2018. Metal-free carbocatalysis in advanced oxidation reactions. Acc. Chem. Res. 51, 678-687. https://doi.org/10.1021/acs. accounts.7b00535.

Fang, G.-D., Dionysiou, D.D., Wang, Y., Al-Abed, S.R., Zhou, D.-M., 2012. Sulfate radicalbased degradation of polychlorinated biphenyls: effects of chloride ion and reaction kinetics. J. Hazard Mater. 227-228, 394-401. https://doi.org/10.1016/j. jhazmat.2012.05.074.

Gao, L., Zhou, F., Chen, Q., Duan, G., 2018. Generation of Pd@Ni-CNTs from polyethylene wastes and their application in the electrochemical hydrogen evolution reaction. ChemistrySelect 3, 5321-5325. https://doi.org/10.1002/slct.201800127.

Gomes, H.T., Miranda, S.M., Sampaio, M.J., Silva, A.M.T., Faria, J.L., 2010. Activated carbons treated with sulphuric acid: catalysts for catalytic wet peroxide oxidation. Catal. Today 151, 153-158. https://doi.org/10.1016/j.cattod.2010.01.017.

Gong, J., Liu, J., Chen, X., Jiang, Z., Wen, X., Mijowska, E., Tang, T., 2014. Striking influence of $\mathrm{NiO}$ catalyst diameter on the carbonization of polypropylene into carbon nanomaterials and their high performance in the adsorption of oils. RSC Adv. 4, 33806-33814. https://doi.org/10.1039/C4RA05016A.

Lehman, J.H., Terrones, M., Mansfield, E., Hurst, K.E., Meunier, V., 2011. Evaluating the characteristics of multiwall carbon nanotubes. Carbon 49, 2581-2602. https://doi. org/10.1016/j.carbon.2011.03.028.

Liu, F., Hashim, N.A., Liu, Y., Abed, M.R.M., Li, K., 2011. Progress in the production and modification of PVDF membranes. J. Membr. Sci. 375, 1-27. https://doi.org/ 10.1016/j.memsci.2011.03.014.

Lutze, H.V., Kerlin, N., Schmidt, T.C., 2015. Sulfate radical-based water treatment in presence of chloride: formation of chlorate, inter-conversion of sulfate radicals into hydroxyl radicals and influence of bicarbonate. Water Res. 72, 349-360. https://doi. org/10.1016/j.watres.2014.10.006.

Marcilla, A., García, Á.N., del Remedio Hernández, M., 2007. Thermal degradation of LDPE-vacuum gas oil mixtures for plastic wastes valorization. Energy Fuel. 21, 870-880. https://doi.org/10.1021/ef0605293.

Matzek, L.W., Carter, K.E., 2016. Activated persulfate for organic chemical degradation: a review. Chemosphere 151, 178-188. https://doi.org/10.1016/j. chemosphere.2016.02.055.

Menezes, H.C., de Barcelos, S.M.R., Macedo, D.F.D., Purceno, A.D., Machado, B.F., Teixeira, A.P.C., Lago, R.M., Serp, P., Cardeal, Z.L., 2015. Magnetic N-doped carbon nanotubes: a versatile and efficient material for the determination of polycyclic aromatic hydrocarbons in environmental water samples. Anal. Chim. Acta 873, 51-56. https://doi.org/10.1016/j.aca.2015.02.063.

Mezni, A., Saber, N.B., Alhadhrami, A.A., Gobouri, A., Aldalbahi, A., Hay, S., Santos, A., Losic, D., Altalhi, T., 2017. Highly biocompatible carbon nanocapsules derived from plastic waste for advanced cancer therapy. J. Drug Deliv. Sci. Technol. 41, 351-358. https://doi.org/10.1016/j.jddst.2017.08.007.

Miller, D.J., Kasemset, S., Paul, D.R., Freeman, B.D., 2014. Comparison of membrane fouling at constant flux and constant transmembrane pressure conditions. J. Membr. Sci. 454, 505-515. https://doi.org/10.1016/j.memsci.2013.12.027.

Miranda, M.N., Silva, A.M.T., Pereira, M.F.R., 2020. Microplastics in the environment: a DPSIR analysis with focus on the responses. Sci. Total Environ. 718 https://doi.org/ 10.1016/j.scitotenv.2019.134968.

Moo, J.G.S., Veksha, A., Oh, W.-D., Giannis, A., Udayanga, W.D.C., Lin, S.-X., Ge, L., Lisak, G., 2019. Plastic derived carbon nanotubes for electrocatalytic oxygen reduction reaction: effects of plastic feedstock and synthesis temperature. Electrochem. Commun. 101, 11-18. https://doi.org/10.1016/j.elecom.2019.02.014. 
Nyakuma, B.B., Ivase, T.J.-P., Emerging trends in sustainable treatment and valorisation technologies for plastic wastes in Nigeria: a concise review. Environ. Prog. Sustain. Energy, e13660. https://doi.org/10.1002/ep.13660.

Oberlin, A., Endo, M., Koyama, T., 1976. Filamentous growth of carbon through benzene decomposition. J. Cryst. Growth 32, 335-349. https://doi.org/10.1016/0022-0248 (76)90115-9.

Okan, M., Aydin, H.M., Barsbay, M., 2019. Current approaches to waste polymer utilization and minimization: a review. J. Chem. Technol. Biotechnol. 94, 8-21. https://doi.org/10.1002/jctb.5778.

Outsiou, A., Frontistis, Z., Ribeiro, R.S., Antonopoulou, M., Konstantinou, I.K., Silva, A. M.T., Faria, J.L., Gomes, H.T., Mantzavinos, D., 2017. Activation of sodium persulfate by magnetic carbon xerogels $(\mathrm{CX} / \mathrm{CoFe})$ for the oxidation of bisphenol A: process variables effects, matrix effects and reaction pathways. Water Res. 124, 97-107. https://doi.org/10.1016/j.watres.2017.07.046.

Oyekunle, D.T., Zhou, X., Shahzad, A., Chen, Z., 2021. Review on carbonaceous materials as persulfate activators: structure-performance relationship, mechanism and future perspectives on water treatment. J. Mater. Chem. 9, 8012-8050. https://doi.org/ 10.1039/D1TA00033K.

Papari, S., Bamdad, H., Berruti, F., 2021. Pyrolytic conversion of plastic waste to valueadded products and fuels: a review. Materials 14, 2586. https://doi.org/10.3390/ ma14102586.

Pinho, M.T., Gomes, H.T., Ribeiro, R.S., Faria, J.L., Silva, A.M.T., 2015. Carbon nanotubes as catalysts for catalytic wet peroxide oxidation of highly concentrated phenol solutions: towards process intensification. Appl. Catal., B 165, 706-714. https://doi.org/10.1016/j.apcatb.2014.10.057.

Pol, V.G., Thackeray, M.M., 2011. Spherical carbon particles and carbon nanotubes prepared by autogenic reactions: evaluation as anodes in lithium electrochemical cells. Energy Environ. Sci. 4, 1904-1912. https://doi.org/10.1039/C0EE00256A.

Qian, F., Luo, J., Yin, H., Liu, F., Gao, S., Gu, X., 2021. Carbonaceous composite membranes for peroxydisulfate activation to remove sulfamethoxazole in a real water matrix. Chemosphere 132597. https://doi.org/10.1016/j. chemosphere.2021.132597.

Ribeiro, R.S., Frontistis, Z., Mantzavinos, D., Venieri, D., Antonopoulou, M., Konstantinou, I., Silva, A.M.T., Faria, J.L., Gomes, H.T., 2016a. Magnetic carbon xerogels for the catalytic wet peroxide oxidation of sulfamethoxazole in environmentally relevant water matrices. Appl. Catal., B 199, 170-186. https://doi. org/10.1016/j.apcatb.2016.06.021.

Ribeiro, R.S., Silva, A.M.T., Figueiredo, J.L., Faria, J.L., Gomes, H.T., 2016b. Catalytic wet peroxide oxidation: a route towards the application of hybrid magnetic carbon nanocomposites for the degradation of organic pollutants. A review. Appl. Catal. B 187, 428-460. https://doi.org/10.1016/j.apcatb.2016.01.033.

Roy, S., Aitipamula, S., Nangia, A., 2005. Thermochemical analysis of venlafaxine hydrochloride polymorphs $1-5$. Cryst. Growth Des. 5, 2268-2276. https://doi.org/ 10.1021/cg0580096.

Serp, P., Machado, B.F., 2015. Nanostructured Carbon Materials for Catalysis. The Royal Society of Chemistry, Cambridge, UK.

Serp, P., Corrias, M., Kalck, P., 2003. Carbon nanotubes and nanofibers in catalysis. Appl. Catal. A 253, 337-358. https://doi.org/10.1016/S0926-860X(03)00549-0.

Sharma, S.S., Batra, V.S., 2020. Production of hydrogen and carbon nanotubes via catalytic thermo-chemical conversion of plastic waste: Review. J. Chem. Technol. Biotechnol. 95, 11-19. https://doi.org/10.1002/jctb.6193.

Silva, T.L.S., Morales-Torres, S., Figueiredo, J.L., Silva, A.M.T., 2015. Multi-walled carbon nanotube/PVDF blended membranes with sponge- and finger-like pores for direct contact membrane distillation. Desalination 357, 233-245. https://doi.org/ 10.1016/j.desal.2014.11.025.

Silva, A.S., Kalmakhanova, M.S., Massalimova, B.K., Sgorlon, J.G., Diaz de Tuesta, J.L., Gomes, H.T., 2019. Wet peroxide oxidation of paracetamol using acid activated and
Fe/Co-pillared clay catalysts prepared from natural clays. Catalysts 9, 705. https:// doi.org/10.3390/catal9090705.

Sousa, J.C.G., Barbosa, M.O., Lado Ribeiro, A.R., Ratola, N., Pereira, M.F.R., Silva, A.M. T., 2020. Distribution of micropollutants in estuarine and sea water along the Portuguese coast. Mar. Pollut. Bull. 154, 111120. https://doi.org/10.1016/j. marpolbul.2020.111120.

Sridhar, V., Park, H., 2020. Transforming waste poly(ethylene terephthalate) into nitrogen doped carbon nanotubes and its utility in oxygen reduction reaction and bisphenol-A removal from contaminated water. Materials 13, 4144. https://doi.org/ $10.3390 / \mathrm{ma13184144.}$

Szabó, A., Perri, C., Csató, A., Giordano, G., Vuono, D., Nagy, J.B., 2010. Synthesis methods of carbon nanotubes and related materials. Materials 3, 3092-3140. https://doi.org/10.3390/ma3053092.

Tessonnier, J.-P., Rosenthal, D., Hansen, T.W., Hess, C., Schuster, M.E., Blume, R., Girgsdies, F., Pfänder, N., Timpe, O., Su, D.S., Schlögl, R., 2009. Analysis of the structure and chemical properties of some commercial carbon nanostructures. Carbon 47, 1779-1798. https://doi.org/10.1016/j.carbon.2009.02.032.

Utetiwabo, W., Yang, L., Tufail, M.K., Zhou, L., Chen, R., Lian, Y., Yang, W., 2020. Electrode materials derived from plastic wastes and other industrial wastes for supercapacitors. Chin. Chem. Lett. 31, 1474-1489. https://doi.org/10.1016/j. cclet.2020.01.003.

Veksha, A., Yin, K., Moo, J.G.S., Oh, W.-D., Ahamed, A., Chen, W.Q., Weerachanchai, P., Giannis, A., Lisak, G., 2020. Processing of flexible plastic packaging waste into pyrolysis oil and multi-walled carbon nanotubes for electrocatalytic oxygen reduction. J. Hazard Mater. 387, 121256. https://doi.org/10.1016/j. jhazmat.2019.121256.

Vieira, O., Ribeiro, R.S., Pedrosa, M., Lado Ribeiro, A.R., Silva, A.M.T., 2020. Nitrogendoped reduced graphene oxide - PVDF nanocomposite membrane for persulfate activation and degradation of water organic micropollutants. Chem. Eng. J. 402, 126117. https://doi.org/10.1016/j.cej.2020.126117.

Wang, J., Shen, B., Lan, M., Kang, D., Wu, C., 2020. Carbon nanotubes (CNTs) production from catalytic pyrolysis of waste plastics: the influence of catalyst and reaction pressure. Catal. Today 351, 50-57. https://doi.org/10.1016/i.cattod.2019.01.058.

Wen, X., Chen, X., Tian, N., Gong, J., Liu, J., Rümmeli, M.H., Chu, P.K., Mijiwska, E., Tang, T., 2014. Nanosized carbon black combined with $\mathrm{Ni}_{2} \mathrm{O}_{3}$ as "universal" catalysts for synergistically catalyzing carbonization of polyolefin wastes to synthesize carbon nanotubes and application for supercapacitors. Environ. Sci. Technol. 48, 4048-4055. https://doi.org/10.1021/es404646e.

Williams, P.T., 2021. Hydrogen and carbon nanotubes from pyrolysis-catalysis of waste plastics: a review. Waste Biomass Valorization 12, 1-28. https://doi.org/10.1007/ s12649-020-01054-w.

Wu, C., Nahil, M.A., Miskolczi, N., Huang, J., Williams, P.T., 2016. Production and application of carbon nanotubes, as a co-product of hydrogen from the pyrolysiscatalytic reforming of waste plastic. Process Saf. Environ. 103, 107-114. https://doi. org/10.1016/j.psep.2016.07.001.

Yin, R., Sun, J., Xiang, Y., Shang, C., 2018. Recycling and reuse of rusted iron particles containing core-shell Fe-FeOOH for ibuprofen removal: adsorption and persulfatebased advanced oxidation. J. Clean. Prod. 178, 441-448. https://doi.org/10.1016/j. jclepro.2018.01.005.

Zhang, J., Xu, Z., Shan, M., Zhou, B., Li, Y., Li, B., Niu, J., Qian, X., 2013. Synergetic effects of oxidized carbon nanotubes and graphene oxide on fouling control and antifouling mechanism of polyvinylidene fluoride ultrafiltration membranes. J. Membr. Sci. 448, 81-92. https://doi.org/10.1016/j.memsci.2013.07.064.

Zhuo, C., Levendis, Y.A., 2014. Upcycling waste plastics into carbon nanomaterials: a review. J. Appl. Polym. Sci. 131 https://doi.org/10.1002/app.39931. 